\title{
Determinant of Households Consumption Behavior in UAE: A Comparison of Nationals and Expatriates
}

\author{
Dr. Marina-Selini Katsaiti, Associate Professor \\ Department of Economics and Finance, UAEU \\ Khalifa Abdulrahman Abdulla Ahmad \\ Hamid Mohammadi Tajuddin \\ Shahabuddin Abdulrouf \\ United Arab Emirates University, Al Ain, UAE
}

doi: 10.19044/esj.2017.v13n16p84 URL:http://dx.doi.org/10.19044/esj.2017.v13n16p84

\begin{abstract}
The United Arab Emirates during the past 45 years has achieved startling economic growth rates; therefore, it is crucial to examine the consumption pattern in the UAE. This study aims to introduce the pattern of the household consumption behavior to the literature. The outcome of this study can provide useful information to policy makers by allowing them to gain important insights on household's consumption needs and expenditure allocation. This study used survey data collected from interviewing random household participants in malls in Dubai, Abu Dhabi, and Alain. On March 2015 a sample of 254 were examined, of men and women, and expatriates and nationals. We investigate consumption habits of the type of goods and services people buy, normal against luxuries. Then, we use empirical estimations to examine the determinants of household expenditures. In our study, we find that in general nationals spend more than expatriates do; for the whole sample, most expenditure is concentrated on food, education, and housing. Our results show that household structure does not affect the consumption behavior of a national household as it does to the expatriates. In addition, younger people consume more than the older ones, while married consume more than the rest.
\end{abstract}

Keywords: Consumption, UAE, Household behavior, Income distribution

\section{Introduction}

The United Arab Emirates during the past 45 years has achieved historical development through startling economic growth rates, having gone through a transition from a Bedouin life to a modern lifestyle. To understand the economic activity it is important that we investigate consumption as it 
represents approximately $70 \%$ of the Gross Domestic Product in any economy. Studying consumption does not only explain the economic wellbeing of the individual or the household, but it also reflects the cultural preferences and behavior in the UAE, and identifies the activity of each production sector by identifying the level of expenditure spent on each sector. In the UAE, to our knowledge, the study of consumption behavior has not yet received the best notice from researchers, except a 2009 studies published by the Dubai Economic Council.

The study of the consumption behavior could be addressed as the investigation of how people manage their income in order to fulfill their needs and wants according to their preferences and the availability of resources (Witt, 2001). This study is crucial in understanding some of the characteristics that explain consumption in the UAE at the micro level. This is evident as public data show a great increase in gross domestic product expenditure in the UAE from 39.87 billion in 1975 at constant prices of 2000, to reach up to 234.97 billion in 2013. Another crucial statistic is the gross domestic product per capita, which decreased from $\$ 74,832.17$ in constant 2000 prices in 1975 to $\$ 25,140.76$ in 2013. Following the decline per capita income, household consumption declined from a $\$ 27,701.95$ at constant prices in 2001 to $\$ 15,097.5$ in 2013. These significant changes however are mostly attributable to the great influx of labor, which drastically affected the population. Studying consumption behavior in the UAE is important in order for policy makers to understand its determinants and adopt appropriate policies during the business cycle. Analyzing the consumption pattern of household against per capita is important in the case of the UAE, since large families and extended family households are most commonly found as compared to the west. In addition, examining some of the determinants of consumption after taking into consideration the differences in preferences based on demographic (such as age, gender, and nationality) and socioeconomic characteristic (i.e. income, employment, etc.) allows for useful conclusions. This results into taking into consideration the preferences of different household members when allocating the available income, which results in having a household aggregated indifference curve rather than individual indifference curve. So as a result, the number of household member and characteristics are more likely to be very decisive in the consumption pattern. Furthermore, higher propensity to consume has shown that it is associated with lower wealth ratios (Lise \& Seitz, 2011).

This paper investigates the determinants of the household consumption behavior and the income allocation of the individual household in the United Arab Emirates. It aims to further investigate the consumption behavior in the UAE. We examine how households with different characteristics and demographics could show a difference in their 
consumption habits. In addition to monitoring their own perspective about their consumption behavior. Last, we investigate how consumption is divided between normal and luxury goods. This study could help policy makers identify priorities for domestic good production in the UAE, given the concentration of household consumption and the availability of resources and the necessary technology. This in turn could help increase GDP through the increase in production and the increase in net exports, through the reduction of imports.

In order to conduct this research we collect primary survey data. Data collection was implemented by interviewing individuals in public places, such as the supermarkets and malls in both Dubai, Abu Dhabi, and Alain. Our sample consists of 254 local and expatriate adult men and women. We conduct statistical analysis to analyze spending behavior and allocation of income. In addition, we investigate the participants perceptions about their allocation of income on different consumption categories, i.e. food, clothes and personal items, transportation, tourism and entertainment, education, communication services, medical services, and housing. We also try to approximate for the share of income consumed by asking how much of total income individuals spend on goods and services. The outcome of this study can provide useful information to policy makers by gaining important insights on consumer needs, income and expenditure allocation, and spending in relation to the family structure.

We expect to find a high portion of income consumed by nationals. Nationals might also consume more than expats because they: i) receive support from the government, ii) have bigger families, and iii) face much less job and financial insecurity, compared to expatriates.

In Section 2 we present the relevant literature. Section 3 presents the data. Section 4 we introduce our data and methodology and in Section 5 we discuss our results. Section 6 concludes.

\section{Literature review}

The studies on the pattern of household expenditures allocation or the determinants of household consumption have been deeply considered in the past decade as one of the crucial topics of the applied economics. Bureaus of research and researchers have been examining this topic to develop a demand function of the consumption pattern, which therefore could explain the total consumption on the aggregate level and gross domestic production. In addition, in any given structural levels of per capita income and prices, income is distributed differently across several expenditure categories (see Barigozzi et al (2009)). Therefore, it is crucial to examine such factors that determine those differences in household consumption (Barigozzi et al, 2009) . The literature have been commonly testing for the Engel's law which 
stated that as income increases the share spent on food decreases (Houthakker (1957) and Barigozzi et al (2009)), results on such tests tend to support this theory(Barigozzi et al, 2009) (Houthakker, 1957).

In 2009, the Dubai Economic Council have published working papers investigating the consumption and spending behavior. Duha Fadel (2009) used the United Arab Emirates income and expenditure survey of 2007/2008. Fadel (2009) investigated the consumption pattern of the low-income households, middle-income, and high-income. For nationals, non-nationals, and mixed nationality. This author focused mainly on investigating the expenditure gap between low-income household and the other two levels of income. Main conclusion was that due to the several governmental policies that aim to provide better living standards for nationals, the gap was found to be unmentionable in all expenditure categories. On the other side, expatriates where found to have a comparably higher gap in expenditures between different income levels. Examining the income elasticity of demand, Fadel (2009) have found that food, beverages, rents, utilities, health care, and Tabaco where necessities for all income levels, with a slight fluctuations due to differences in income. Transportation and communication had an elasticity of one, whereas clothes, footwear, furniture, education, entertainment, and several services were found to be highly elastic (Fadel, 2009).

Witt (2001) defines consumption as the money paid for a good or service by a consumer, with the exception of using it for further exchanges and profits. One point that the theory of consumption does not normally take into consideration is that higher income does not always result in an increase in consumption. For example, having an increase in income might lead to substituting to another good rather than buying more of that good (Witt, 2001).

Lise and Seitz (2011) categorized three kinds of consumption, i.e. leisure, private goods, and public goods. They find that consuming more leisure will lead to less consumption of goods. In addition, having a family member that you can spend time with, gives more value to leisure. When investigating both spouses patterns, it is found that the decision of each spouse on whether to work also depend on the other. This will reflect on the consumption level of the household. Turning into consumption inequality within the households, Lise and Seitz (2011) suggested that it is wrong to assume that consumption does not vary with the source of income in the household, since it is shown that the share of wife's income on total household has drastically changed over time (Lise \& Seitz, 2011).

Another study by Sekhampu and Niyimbanira (2013) conducted in South Africa shows significant results regarding household expenditures. With monthly expenditures being $\$ 135.719$ on average, food is found to 
have the largest share, while other expenditures such as entertainment, house expenses (i.e. rent, electricity, and furniture), transportation, and insurance, all added up contribute to half the total expenditure. Income per month was found to be $\$ 149.36$ on average, with wage contributing only half and government grants representing the other half. Significant demographics that increase expenditure were number of people in the household and their employment status. The educational level of the head of the household had a significant effect and being married obviously incurs higher expenditures (Sekhampu \& Niyimbanira, 2013).

According to the official of publications of the European Committee, it has witnessed a decrease in the growth rate of consumption since 1999, with the highest rate being of Ireland and least in Denmark during that period. Major expenditures are food, housing, and transportation. During that period, food's share of total expenditure decreased, and housing and transportation increased with economic development. As expected higher food expenditures were associated with lower prices on food. Housing had the highest share of expenditure in the EU, with its prices increasing more than the quantity supplied. In addition to that, in relation to the evolution of the countries, spending on communication has been increasing. On the other hand, expenditures on alcohol, tobacco, hotels, and restaurants account total for almost $20 \%$ of total expenditures in the EU, with the northern countries exhibiting the highest shares. Clothing and footwear, furnishings, household equipment, routine maintenance of the house, and communication, were found to be almost 30\% in total expenditures. As for health and education, they represent almost $2 \%$ each. While for personal care, insurance, financial services, and social protection, represent almost 10\% (European Committee, 2002).

According to Ryan (2003), consumption in Ireland experienced a decrease in the 80's followed by an increase in the 90's. Food, rent, entertainment and education have all experienced a steady growth during that period of approximately four percentage points. The increase in income in Ireland could perfectly explain the growth in clothes, transport and communication, equipment and accessories, and durable goods. Taking into consideration the long-term and short-term effects on consumption, Ryan (2003) defines long-term determinants as disposable income and wealth. His findings show that income effects are stronger in determining the level of consumption compared to wealth. In the short-term, unemployment and interest rates were the main determinants with interest rates being as the opportunity cost of consumption (Ryan, 2003).

In the last two decades, Australia has experienced a tendency towards buying less goods and more services. Having a nominal increase in expenditures is mainly caused by inflation. As expected, low-income 
individuals were found to spend much less on services (such as hotels, restaurants, cafes) against goods (such as food), while the richer people moved from spending more on goods to spending more on services. This is consistent with the trend observed in many developed countries; as people get richer, spending on services gets more than that on goods. Overall, older households were found to spend less than the younger ones. However, in contrast, the growth of expenditure was higher for old households than young ones. In addition to that, older people increased their spending on services. Because of government transfers, older people had a higher growth in income (Beech et al, 2014).

Çağlayan and Astar (2012) find that men consume less than women do, while age has a positive effect on consumption. With regards to the household structure, a house with a husband, wife, and kids has a higher expenditure than a house with one member, while at the individual level single people spend more compared to married, widowed, or divorced. In addition, the availability of social security leads to higher consumption. Considering the region, people living in rural areas faced a lower expenditure level than in the urban areas. Education had a significant effect of increasing consumption too. As expected, home ownership leads to greater total consumption as compared to renting a house (Çă̆layan \& Astar, 2012).

According to Rani (2014), the cultural background; strongly related to the country of origin; is crucial when it comes to understanding the needs and behaviors of an individual. Other factors include lifecycle stage, occupation, economic circumstances, lifestyle, and personality. These may explain why our preferences often change as our situation changes. Decisions and buying behavior are obviously also influenced by the characteristics, motivation, perception, and learning as well as beliefs and attitudes (Rani, 2014).

Barigozzi et al (2009) examined the household expenditures in Italy focusing on the period from 1989 to 2004 using the Survey of household income and wealth provided by the bank of Italy. They investigated expenditure on non-durable goods (including food), durable goods, and insurance. They have found that overall household consumption among several expenditure categories have been constant throughout the period, whereas expenditure on insurance increased during the late 90's. Income was also found to be an increasing factor of the total consumption. On the other hand, they have found a strong and positive correlation between all expenditures. In addition to examining the household consumption expenditure, they show a descriptive analysis of the household budget share; $68 \%$ have been allocated in non-durable goods with food accounting for only $33 \%$. In contrast, only $15 \%$ and $5 \%$ of the total budget have been spent on durable goods and insurance respectively. While taking into consideration 
the budget share, analysis show a negative correlation between non-durable goods (including food) and durable goods, whereas no correlation was found between either categories with insurance (Barigozzi et al, 2009).

One of the first to examine the household consumption was Houthakker (1957), using 40 surveys in 30 different countries to study an international pattern of the household consumption. The paper focused on several expenditure categorise, i.e.food, housing, clothing, and all other items. In addition to examining the effect of the family size. His paper found that food is strongly correlated with the size of the family, and the share of income spent on food was found to be decreasing as income increases. Clothing was found to be a luxurious item. Housing, on the other hand, was found to be a necessity as a whole, but, was also found to be affecting differently in different countries due to differences in rent factors. Other items have been found to affect differently, transportation was analyzed as a necessity in some countries, whereas entertainment was found to be negatively correlated with family size. The expenditures categories were found to be related to each other when considering the family size, because as family size becomes bigger, given the same income, the family becomes relatively poorer (Houthakker, 1957) .

\section{Data}

In this paper, we have studied the household expenditure behavior in the UAE. Our data consists of 254 individuals. Our survey took place on March 2015, it asked questions on nationality, gender, age, education, location, employment status, marital status, number of household members living under the same roof, and how many of them receive their own income. In addition to that, we have asked the participants about their level of income (in ranges), percentage of income consumed, and their perception on the sufficient amount of money needed to maintain a good living standard. We have asked participants about the share of income spent on food, clothing and personal care items, transportation, housing, medical services, education, tourism and entertainment, and communication services. Last, we ask them whether they consider the goods they buy as normal or luxurious.

Surveys were conducted in shopping malls in Dubai, Alain, and Abu Dhabi. All interviews were held during the weekends to have the best representative sample since households tend to go to malls during the weekends more often than in the weekdays. Summary statistics are shown in Table 1 below. 
Table 1: Summary Statistics of examined sample in the survey

Variable

Add unit

Female

age

Emirati

education

Elders in the household

Adults in the household

children above 18 in the household

children under 18 in the household

Maids in the household

total house hold members

Share of income consumed

perceptions on income adequacy married

private sector not working

Income less than 10,000

Income between 10,000 - 15,000

Income between 15,000 - 22,000

Income between 22,000 - 45,000

Income more than 45,000
Observations

252
231
247
250
180
235
173
203
171
253
242
242
248
208
247
243
243
243
243
243

Mean

0.3930

30.0130

0.2910

2.7200

1.2940

2.2090

1.0810

1.7340

0.9420

5.7390

1.4710

2.1980

0.5440

0.4950

0.1780

0.2390

0.1730

0.0620

0.3460

0.1810

Std. Dev. Min Max

Source: Determinants of household consumption survey, Results found using Stata program, 2015

Graphs below use the data collected in the survey of the determinants of the household consumption behavior.

In the household's perceptions on their expenditures allocation, the survey asked participants to represent their consumption allocation in a scale from one to ten for each category. Results are then transformed into decimals to be able to notice the slightest differences. Greater numbers represent higher share of income spent on that good. The following charts illustrate spending differences by nationality and age, given individual perceptions on consumption.

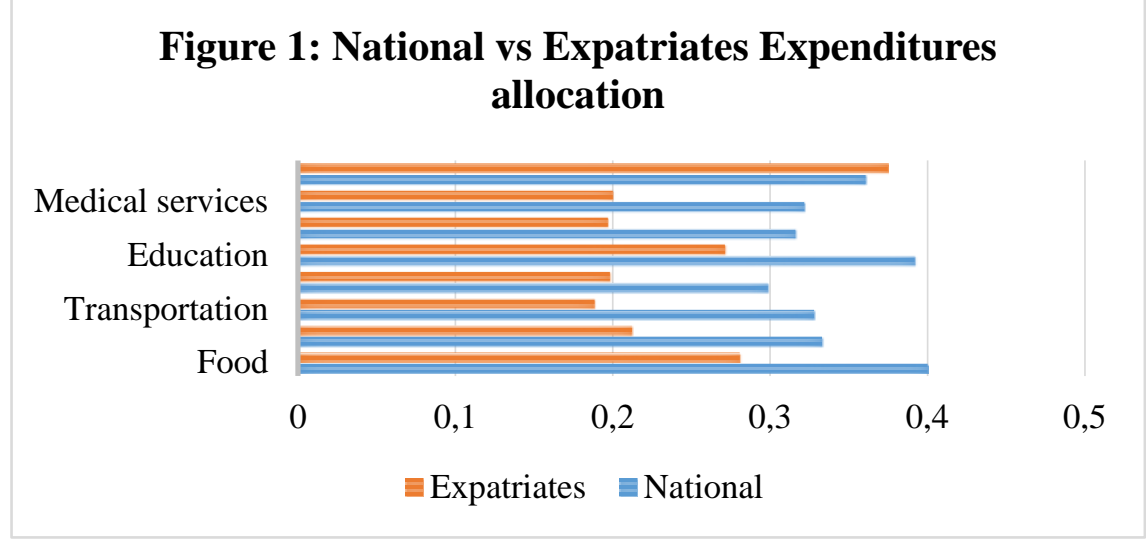


Figure 2: Nationals vs Expatriates Expenditures

Luxury

N Nationals $\equiv$ Expatriates

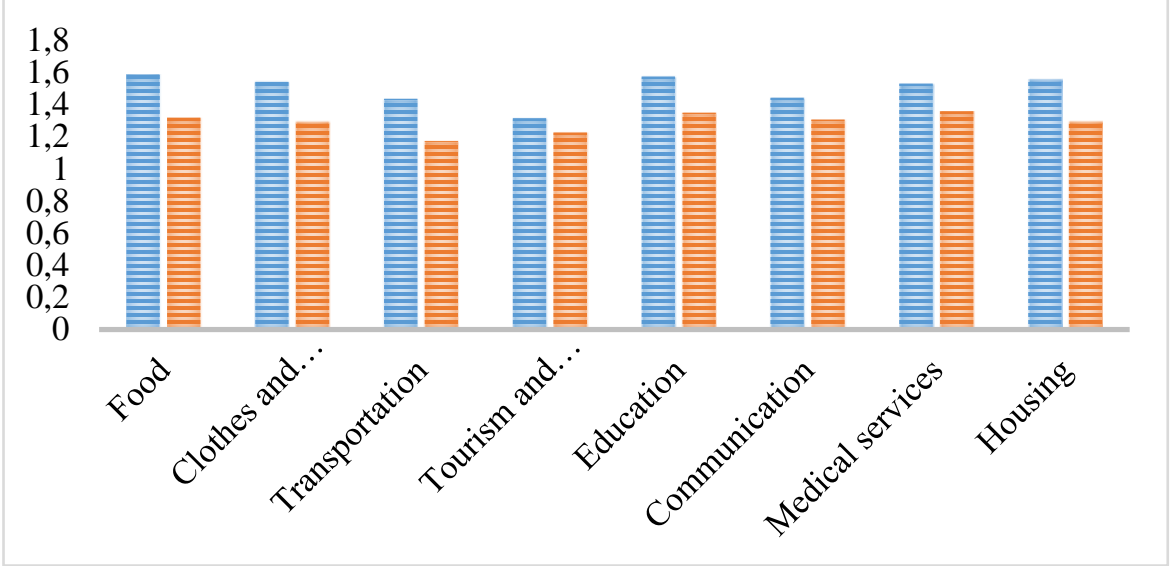

In figure 1, we see the consumption allocation of national against expatriates in our sample. Overall, we have eight items in the expenditures; housing, medical services, communication, education, tourism and entertainment, transportation, clothes and personal care items, and food. In comparison, notice that this only records the feeling of expenditure rather than the accurate amount. We can see that overall, nationals spend more than expatriates in all types of goods and services, except when it comes to housing, whereas the spending on housing for the expatriates is almost equal to that of nationals. In figure 2, it can be stated that there is no much differences between nationals and expatriates in their luxury spending.

In figure 3, we examine the differences in expenditure allocation in age cohorts; we separated age based on three age categories: i) individuals under 25 years of age, ii) between 25 and 40, and iii) over 40. As shown in the chart, we can conclude that younger consumers report a higher share of income spend on expenditures, this result might be due to the habits of a younger participants, or because they have lower income as demonstrated in figure 4 . 


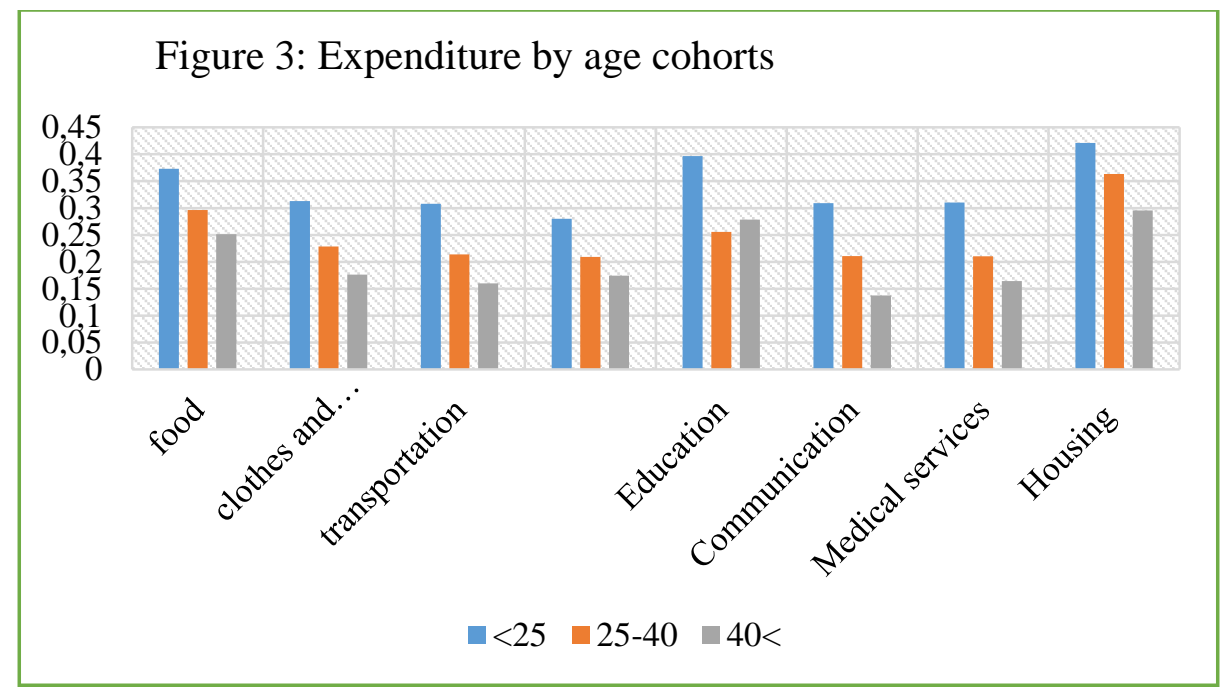

Figure 4: Total income of different age cohorts

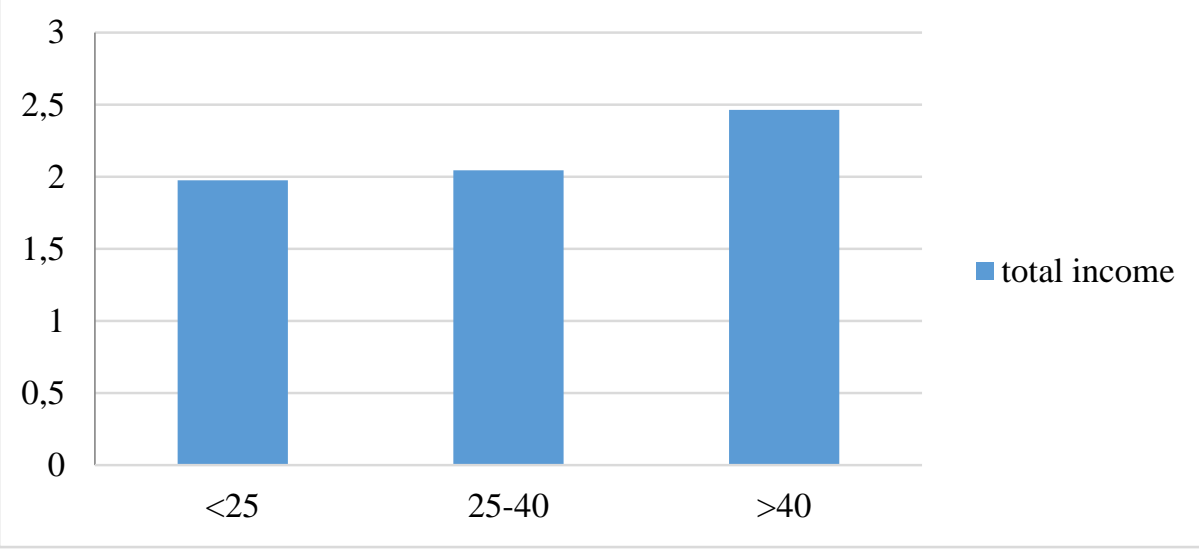

Figure 4 represents total income mapped against age cohorts similar to figure 3. As monitored, we can state that income between under 25 years old is not different from the income of 25 and 40 years old, but when looking at the people above 40 years old we can see an increase in income into a different range. This might be due to that they have better qualifications in work therefore they receive a higher salary, however, this difference in income range between age cohorts reflects on the consumption proportion of income spent by each cohort.

Moving to figures 5 and 6, here we demonstrate the summary statistics of the number of households in our sample. Overall, the highest concentration of our sample was in between 3-6 members, second highest is from 7-10 members. As shown in the following two graphs, figure 5 demonstrates the national households numbers, we can see that most of the 
national houses consist of mostly 7-10 members, then comes from 3-6, and third highest is from 11-14. In contrast, in figure 6 most of the expatriates houses show that they consist of 3-6 members, while in our sample we have an equal number of houses with 2 members of expats and houses with 7 to 10 members, also a house with only one individual showed to be in third place in the expatriates household.

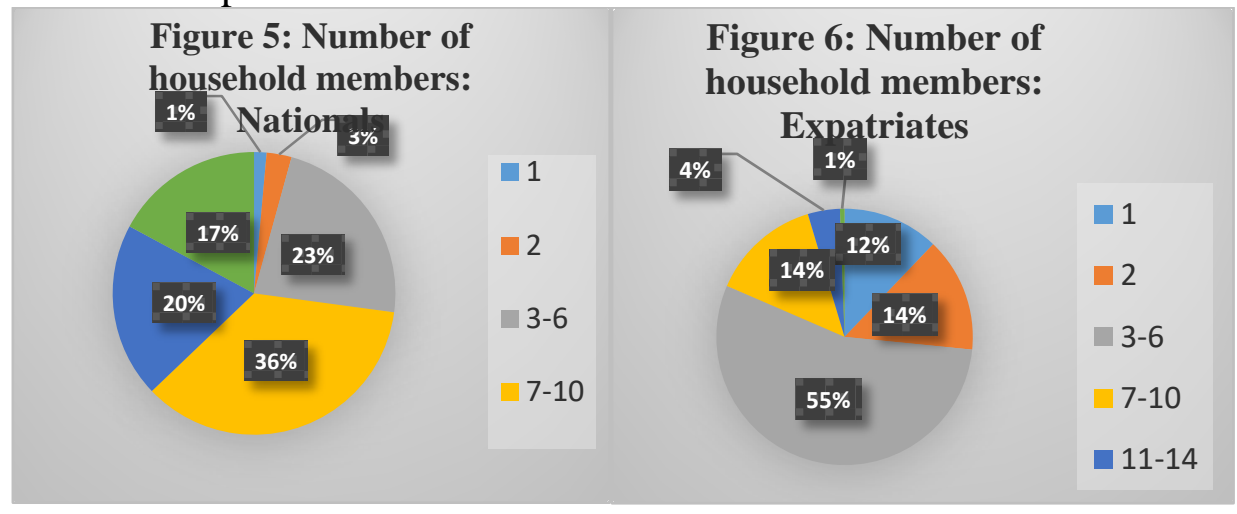

In figure 7 and 8, we show the share of income consumed of both expatriates and nationals respectively. As shown in figure 7, we can see that most of the expatriates in our sample consume less than $50 \%$ and between $50 \%$ and $60 \%$ of their total income. As shown, almost $70 \%$ of the expatriates consume either less than $50 \%$ or between $50 \%$ and $60 \%$. On the other side, in figure $8,70 \%$ of nationals consume in three categories; less than $50 \%$, between $50 \%$ and $60 \%$, and between $60 \%$ and $70 \%$. In which we can conclude that nationals vary more between each other in their consumption pattern than the expatriates do.

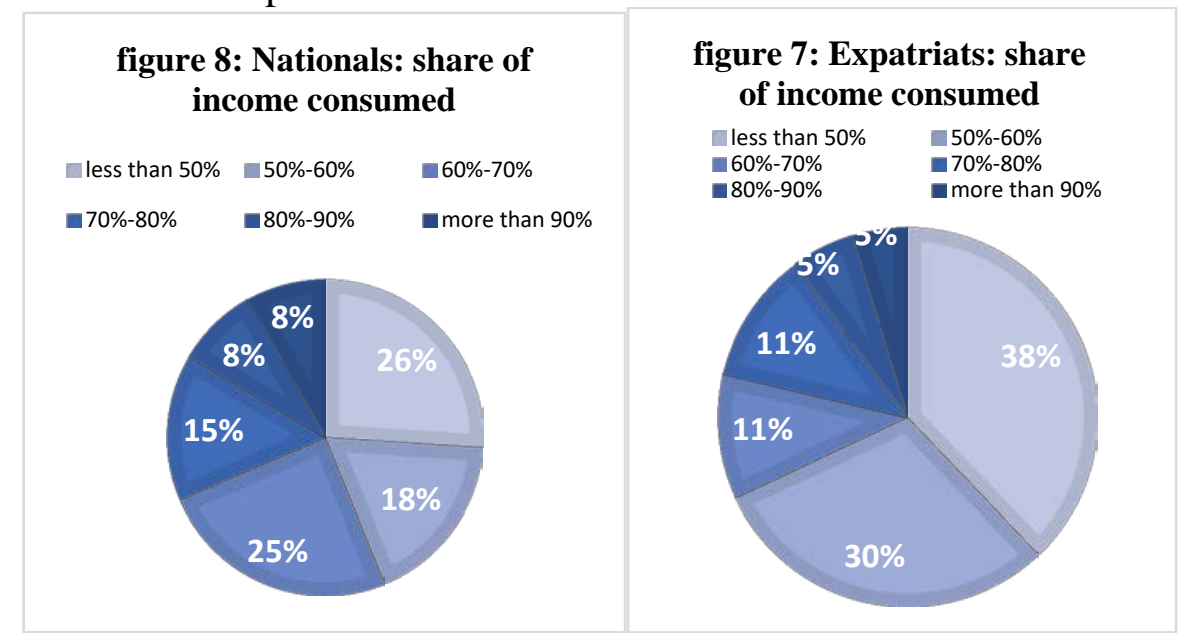




\section{Empirical Estimations}

The methodology followed in this study, similar to the work of Sekhampu and Niyimbanira (2013) and Çağlayan and Astar (2012), the model presents the characteristics as an independent variable and the percentage of consumption as a dependent variable [8] [11].

\section{Empirical Model}

$$
\begin{array}{r}
y_{i}=\beta_{0}+\beta_{1} \cdot \text { fem }+\beta_{2} \cdot \text { age }+\beta_{3} \cdot \operatorname{mar}+\beta_{4} \cdot \text { nat }+\beta_{5} \cdot \text { emt }+\beta_{6} \cdot \text { edc } \\
+\beta_{5} \cdot \text { nt wrk }+\beta_{6} \cdot \text { prt }+\beta_{7} \cdot \text { h } h+\beta_{8} \cdot \text { inc }+\beta_{9} \cdot \text { per inc }+\varepsilon_{i}
\end{array}
$$

Our dependent variable is household consumption as a share of total income. We investigate this by asking participants "what is the percentage of total household income do you spend on goods and services per month". Answers were provided into categories as in: a. less than $50 \%$, b. between $50 \%$ and $60 \%$, c. between $60 \%$ and $70 \%$, d. between $70 \%$ and $80 \%$, e. between $80 \%$ and $90 \%$, f. more than $90 \%$.

Our control variables are gender, age, educational level, and number of members living in a household, income range, perceptions on income adequacy, marital status, UAE nationality dummy, employment status, and working in the public or the private sector. In addition to that, we control for the emirate of residence and the region of origin. Ranges on income and adequate income are divided in five groups: 1 . less than 10,000, 2 . between 10,000 and 15,000, 3. between 15,000 and 22,000, 4. between 22,000 and 45,000, 5. more than 45,000.

Since our dependent variable is categorical and ordered it is necessary to use an ordered probit or ordered logit model. Since our dependent variable is normally distributed, we run ordered probit regressions (empirical model results in annex).

\section{Results}

The following results show that younger cohorts consume less of their share of total income. One interpretation of the result could be because young people tend to spend more since they have fewer responsibilities, also in a younger age they are less concerned with their savings. Another expected result is that married individuals spend more. Married individuals have larger families and including kids and thus have a higher consumption proportion because of the responsibility that follows marriage as in the needs considered at least as bigger houses, more food, expenditure on education, etc.

Our regression results show an increase in consumption with a greater number of household members. However, when interacting Emiratis with the number of household members we find that the marginal $(0.15+(-$ 0.13) effect is positive and significant but net effect has significantly 
decreased to 0.02 , which can be probably explained by stating that the number of household members affects the expatriates consumption level while for Emiratis it doesn't seem to be that important. This case is consistent with the fact that because of the governmental support for the nationals that covers much of their children, elder, and in most cases their marriage expenditures. As a result, the income burden on the head of the household for the Emiratis is much lower compared to the expatriate's household who does not receive such support and should pay for these expenses on his own. Perceptions on income adequacy returns a positive and significant coefficient, which is an expected result. The greater share of income people spend, the more they will think they need.

We also find "not working" to have a positive and significant effect on the consumption share. In this matter, we can suggest that maybe within the household; people who do not work and receive the money from the head of the household tend to have a perception of higher consumption level than what the head of the household who definitely has a much more accurate idea of where exactly the money goes.

\section{Conclusion}

In conclusion, this paper has examined the household expenditures behavior in the UAE for both nationals and expatriates. This paper investigates the determinants of consumption in the household and examines the allocation of income between different kinds of goods and services. We used survey data collected by interviewing participants in Dubai, Abu Dhabi, and Alain. Our sample includes 254 individuals. The importance of this topic is derived from the importance of consumption to the UAE. In the recent years, we have not noticed a large attention of researchers on either examining the household income allocation or testing for determinants of household expenditures. In our study, we find that nationals spend more than expatriates; most expenditure is concentrated on food, education, and housing. This paper has found that there are differences between national's household consumption behavior and the expatriates. More specifically, we find that household structure does not affect the consumption behavior of a national household as it does to the expatriates. Last, but not least, we find that younger people consume more than the older ones, while married consume more than the rest.

\section{Acknowledgement}

We would like to thank the UAEU Ethics Committee for providing us prompt response and approval to our survey, Dr. Mahmoud Al-Iriani for his valuable consultancy while choosing the topic, Dr. Amany A. El Anshasy 
who gave us valuable feedback on our questionnaire, and the UITS at UAEU for providing us iPads that facilitated the data collection.

\section{References:}

1. Amy Beech, Rosetta Dollman, Richard Finlay, and Gianni La Cava. "The Distribution of Household Spending in Australia." Reserve Bank of Australia. 2014.

2. Barigozzi, Matteo, Lucia Alessi, Marco Capasso, and Giorgio Fagiolo. The distribution of households consumption-expenditure budget shares. No. 1061. European Central Bank, 2009.

3. Çăglayan, Ebru, and Melek Astar. "A Microeconometric Analysis of Household Consumption Expenditure Determinants for Both Rural and Urban Areas in Turkey." American International Journal of Contemporary Research 2, no. 2 (2012): 27-38.

4. Fadel, Duha. "The spending pattern of the low income households in the UAE.” Dubai Economic Council, Working paper 08-09, (2009).

5. Houthakker, Hendrik S. "An international comparison of household expenditure patterns, commemorating the centenary of Engel's law." Econometrica, Journal of the Econometric Society (1957): 532-551.

6. Lise, Jeremy, and Shannon Seitz. "Consumption inequality and intra-household allocations." The Review of Economic Studies 78, no. 1 (2011): 328-355.

7. Office of the Official Publications of the European Committee, 2002 "Household final consumption expenditure in the European Union Data 1995-99.” Luxemburg: Office of the Official Publications of the European Committee, 2002.

8. Pinki Rani. "Factors influencing consumer behavior." international Journal of Current Research and Academic Review. 2014.2(9): 52-61.

9. Public Data. Retrieved from: www.google.com

10. Ryan, Mary. "Patterns and determinants of Irish consumption." Central Bank of Ireland, Quarterly Bulletin, Summer (2003): 67-89.

11. Sekhampu, T. J., and F. Niyimbanira. "Analysis of The Factors Influencing Household Expenditure In A South African Township." International Business \& Economics Research Journal 12, no. 3 (2013): 279-284.

12. Witt, Ulrich. "Learning to consume-A theory of wants and the growth of demand." Journal of Evolutionary Economics 11, no. 1 (2001): 23-36. 


\section{Annex:}

\begin{tabular}{|c|c|c|c|c|c|c|c|c|c|c|c|}
\hline \multicolumn{12}{|c|}{ Empirical Model Results } \\
\hline \multirow{2}{*}{$\begin{array}{c}\text { Dependent Variable: } \\
\text { Share of income Consumed } \\
\text { VARIABLES }\end{array}$} & \multirow[b]{2}{*}{-1} & \multirow[b]{2}{*}{-2} & \multirow[b]{2}{*}{-3} & \multirow[b]{2}{*}{-4} & \multirow[b]{2}{*}{-5} & \multirow[b]{2}{*}{-6} & \multirow[b]{2}{*}{-7} & \multirow[b]{2}{*}{-8} & \multicolumn{3}{|c|}{$\begin{array}{c}\text { z-value in parentheses } \\
* * * \mathrm{p}<0.01, * * \mathrm{p}<0.05, * \mathrm{p}<0.1\end{array}$} \\
\hline & & & & & & & & & -9 & -10 & -12 \\
\hline \multirow[t]{2}{*}{ Gender } & 0.23 & $0.30 *$ & $0.30 *$ & 0.26 & $0.33^{*}$ & $0.33^{*}$ & 0.21 & $0.32 *$ & 0.22 & $0.34 *$ & 0.31 \\
\hline & [1.50] & [1.85] & [1.86] & {$[1.45]$} & {$[1.74]$} & {$[1.78]$} & {$[0.87]$} & {$[1.68]$} & {$[0.90]$} & {$[1.78]$} & {$[1.62]$} \\
\hline \multirow[t]{2}{*}{ Age } & $-0.02 * * *$ & $-0.03 * * *$ & $-0.02 * * *$ & $-0.02 * * *$ & $-0.02 * *$ & $-0.02 * * *$ & $-0.02 * *$ & $-0.02^{* *}$ & $-0.02 * *$ & $-0.02 * *$ & $-0.02 * *$ \\
\hline & {$[-2.76]$} & {$[-3.20]$} & {$[-3.03]$} & {$[-2.84]$} & {$[-2.50]$} & {$[-2.70]$} & {$[-2.31]$} & {$[-2.59]$} & {$[-2.12]$} & {$[-2.45]$} & {$[-2.50]$} \\
\hline \multirow[t]{2}{*}{ Married } & & $0.48 * * *$ & $0.49 * * *$ & $0.48^{* * *}$ & $0.51^{* * *}$ & $0.52 * *$ & $0.97 * * *$ & $0.50 * * *$ & $0.89 * * *$ & $0.47 * *$ & $0.45^{* *}$ \\
\hline & & {$[2.73]$} & {$[2.77]$} & {$[2.70]$} & {$[2.68]$} & {$[2.71]$} & [3.88] & {$[2.61]$} & {$[3.50]$} & {$[2.42]$} & {$[2.29]$} \\
\hline \multirow[t]{2}{*}{ Emirati } & & 0.28 & 0.27 & 0.26 & 0.34 & 0.14 & & 0.09 & & 0.09 & $0.73^{*}$ \\
\hline & & {$[1.62]$} & {$[1.53]$} & {$[1.50]$} & [1.57] & {$[0.59]$} & & {$[0.33]$} & & {$[0.37]$} & {$[1.70]$} \\
\hline \multirow[t]{2}{*}{ Education } & & & -0.07 & -0.05 & -0.01 & 0.01 & -0.05 & 0 & -0.09 & -0.04 & -0.05 \\
\hline & & & {$[-0.97]$} & {$[-0.73]$} & {$[-0.08]$} & {$[0.16]$} & {$[-0.49]$} & {$[0.00]$} & {$[-0.79]$} & {$[-0.46]$} & {$[-0.52]$} \\
\hline \multirow[t]{2}{*}{ Not Working } & & & & 0.16 & $1.01 * *$ & $0.82 *$ & 0.58 & $0.84^{*}$ & 0.69 & $0.97 * *$ & $1.11^{* *}$ \\
\hline & & & & {$[0.70]$} & {$[2.44]$} & [1.92] & [1.03] & [1.94] & {$[1.22]$} & {$[2.21]$} & {$[2.50]$} \\
\hline \multirow[t]{2}{*}{ Private Sector } & & & & & 0.05 & 0.13 & 0.31 & 0.14 & 0.36 & 0.2 & 0.25 \\
\hline & & & & & {$[0.28]$} & {$[0.69]$} & [1.30] & {$[0.67]$} & [1.48] & {$[0.96]$} & {$[1.20]$} \\
\hline \multirow[t]{2}{*}{ \# hh members } & & & & & & $0.05^{* *}$ & 0.04 & $0.05^{*}$ & 0.04 & $0.05 * *$ & $0.09 * * *$ \\
\hline & & & & & & {$[1.98]$} & {$[0.96]$} & [1.84] & [0.99] & [1.89] & {$[2.63]$} \\
\hline \multirow[t]{2}{*}{ Total income } & & & & & & & -0.01 & 0.03 & -0.06 & -0.05 & -0.05 \\
\hline & & & & & & & {$[-0.07]$} & {$[0.34]$} & {$[-0.73]$} & {$[-0.60]$} & {$[-0.68]$} \\
\hline \multirow[t]{2}{*}{ Adequate income } & & & & & & & & & $0.18 * *$ & $0.23^{* * *}$ & $0.23 * * *$ \\
\hline & & & & & & & & & {$[2.04]$} & [3.12] & {$[3.09]$} \\
\hline \multirow[t]{2}{*}{ \# hh members x Emirati } & & & & & & & & & & & $-0.09 * *$ \\
\hline & & & & & & & & & & & {$[-1.84]$} \\
\hline Expats Region & & & & & & & Yes & & Yes & & \\
\hline Emirate & & Yes & Yes & Yes & Yes & Yes & Yes & Yes & Yes & Yes & Yes \\
\hline Observations & 219 & 211 & 210 & 209 & 180 & 180 & 133 & 177 & 133 & 176 & 176 \\
\hline R-squared & 0.02 & 0.05 & 0.05 & 0.05 & 0.06 & 0.07 & 0.12 & 0.06 & 0.13 & 0.08 & 0.09 \\
\hline
\end{tabular}

